Supplementary Material for:

\title{
Epoxidation and 1,2-dihydroxylation of alkenes by a nonheme iron model system - DFT supports the mechanism proposed by experiment
}

\author{
Peter Comba* and Gopalan Rajaraman \\ Universität Heidelberg, Anorganisch-Chemisches Institut, \\ INF 270, D-69120 Heidelberg, Germany \\ Phone: +49-6221-548453, Fax: +49-6226-548453, \\ e-mail: peter.comba@aci.uni-heidelberg.de
}

\section{Contents:}

a) Scheme with the three possible singlet states for the $\mathrm{Fe}^{\mathrm{IV}}=\mathrm{O}$ unit and a short discussion on the energetics of singlet states.

b) Plots of the molecular orbitals of the corresponding singlet state A.

c) The optimized structure of the corresponding singlet state $C$.

d) Plots of the molecular orbitals of the corresponding singlet state $\mathrm{C}$.

e) Optimized structure of $\left[\left(\mathrm{L}^{1}\right) \mathrm{Fe}^{\mathrm{IV}}=\mathrm{O}\right]^{2+}$ in the $\mathrm{S}=1$ state together with MOs.

f) Optimized structure of the putative transition state $t s I$ of the concerted path on the $S=1$ surface, and the relevant relaxed potential energy scan.

g) Optimized structures of transition states and intermediates for the catalytic reaction with the $\left[\left(\mathrm{L}^{1}\right) \mathrm{Fe}=\mathrm{O}\right]^{2+}$ complex.

h) List of imaginary frequencies found for the computed transition states.

i) MECP energy profile 
There are three possible singlet states for $\mathrm{Fe}^{\mathrm{IV}}=\mathrm{O}$ complexes (see Scheme $\mathrm{S} 1$ ).

A

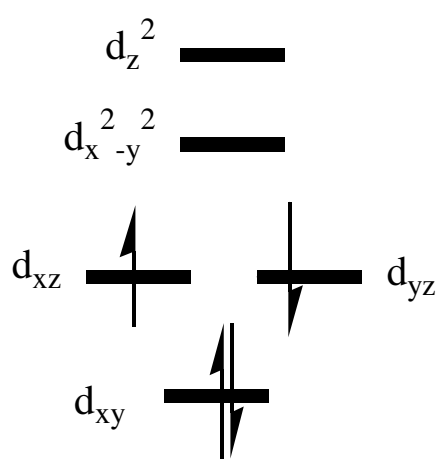

B

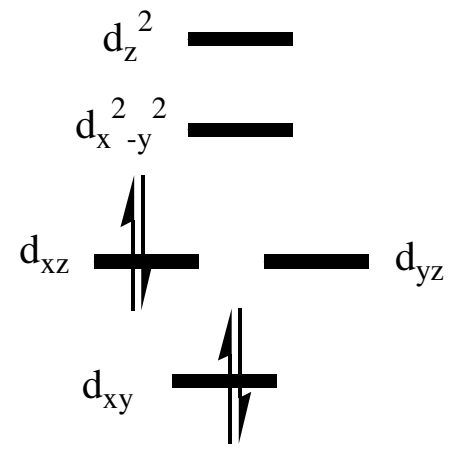

$\mathrm{C}$

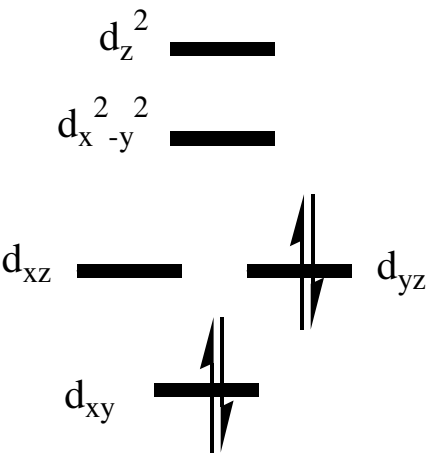

\section{Scheme S1.}

Singlet state $\mathrm{A}$ is $127.1 \mathrm{~kJ} / \mathrm{mol}$ higher in energy than the ground state triplet. The very high energy of the singlet state is expected from the asymmetry of the ligand backbone, and it is also consistent with the fact that no $\mathrm{Fe}^{\mathrm{IV}}=\mathrm{O}$ model complex with a singlet ground state has been characterized so far. The singlet states $\mathrm{B}$ and $\mathrm{C}$ were found to be $23.6 \mathrm{~kJ} / \mathrm{mol}$ lower in energy than singlet state A. It is important to note that singlet states B and C should be degenerate (degeneracy of the $\mathrm{d}_{\mathrm{yz}}, \mathrm{d}_{\mathrm{xz}}$ orbitals). DFT is not well suited to investigate this, and an overestimation of the corresponding energy difference is likely. The calculated spin contamination $\left(<\mathrm{S}^{2}>\right)$ for singlet state A is 0.00 as expected for a pure singlet state. However the $\left\langle\mathrm{S}^{2}>\right.$ of the singlet state $\mathrm{C}$ is 1.041 and this substantially deviates from the expected value of 0.00 and, therefore, its energy and wavefunction should be treated with care. The orbitals of the singlet state A have significant metallic character and are plotted in Figure SF1. The optimized structure of singlet state $\mathrm{C}$ together with the calculated spin densities is given in Figure SF2. The molecular orbitals of singlet state C are shown in Figure SF3. 

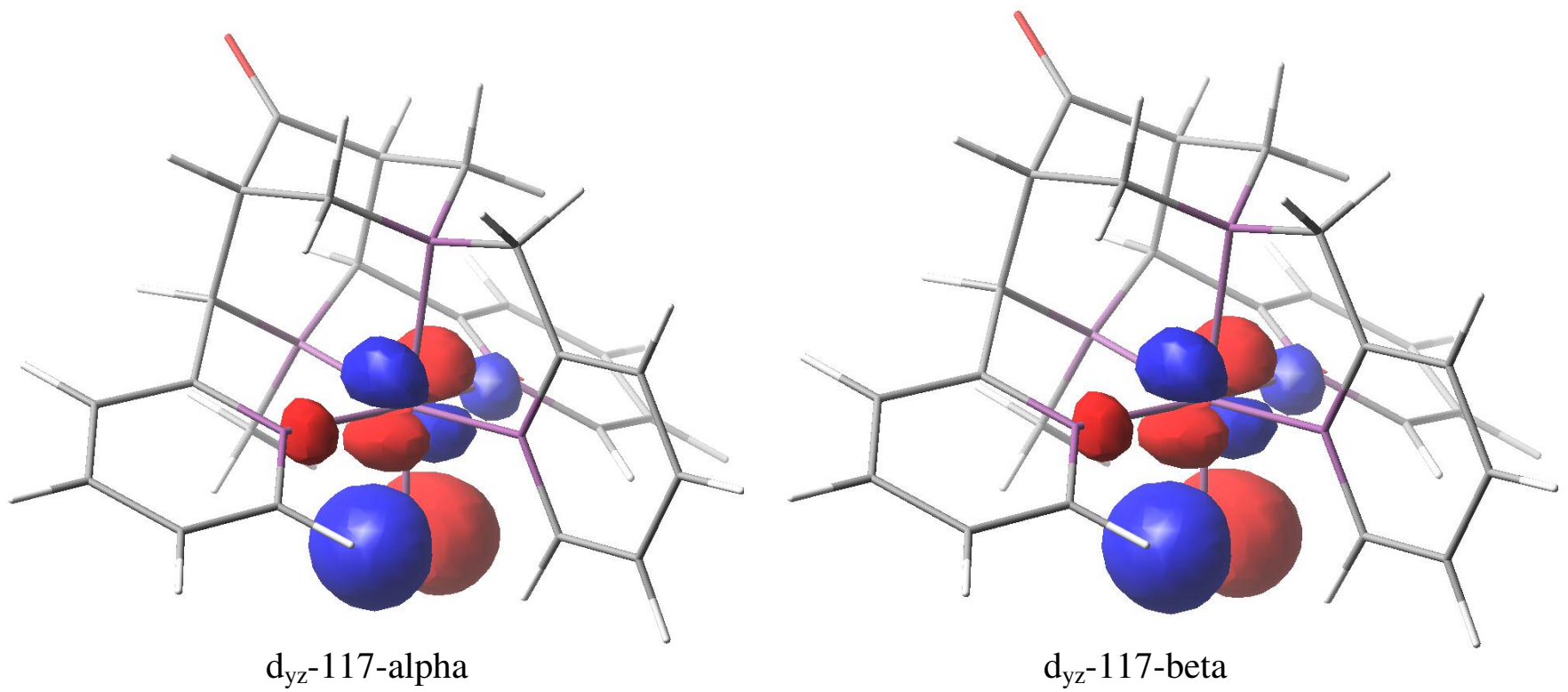

Figure SF1. Molecular orbitals of the $\mathrm{Fe}^{\mathrm{IV}}=\mathrm{O}$ unit of singlet state $\mathrm{A}$ (see Scheme $\mathrm{S} 1$ ) of $\left[\left(\mathrm{L}^{2}\right) \mathrm{Fe}^{\mathrm{IV}}=\mathrm{O}\right]^{2+}$.

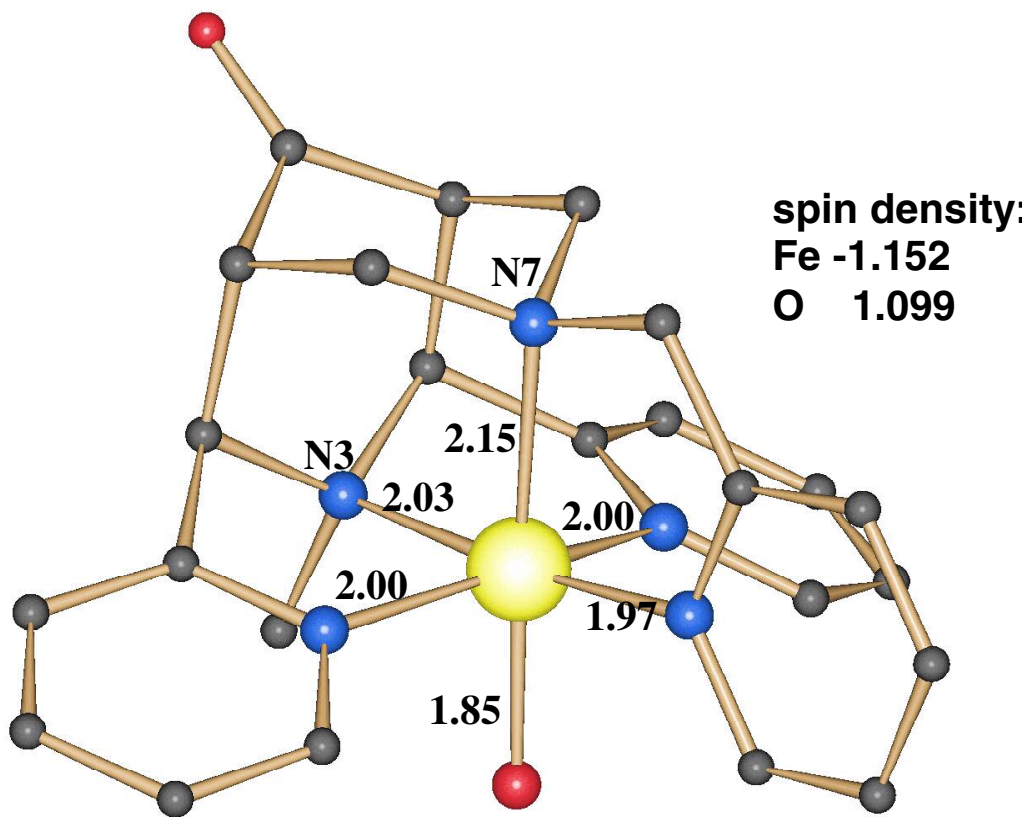

Figure SF2. B3LYP optimized structure of singlet state C (see Scheme S1) of $\left[\left(\mathrm{L}^{2}\right) \mathrm{Fe}^{\mathrm{IV}}=\mathrm{O}\right]^{2+}$. 


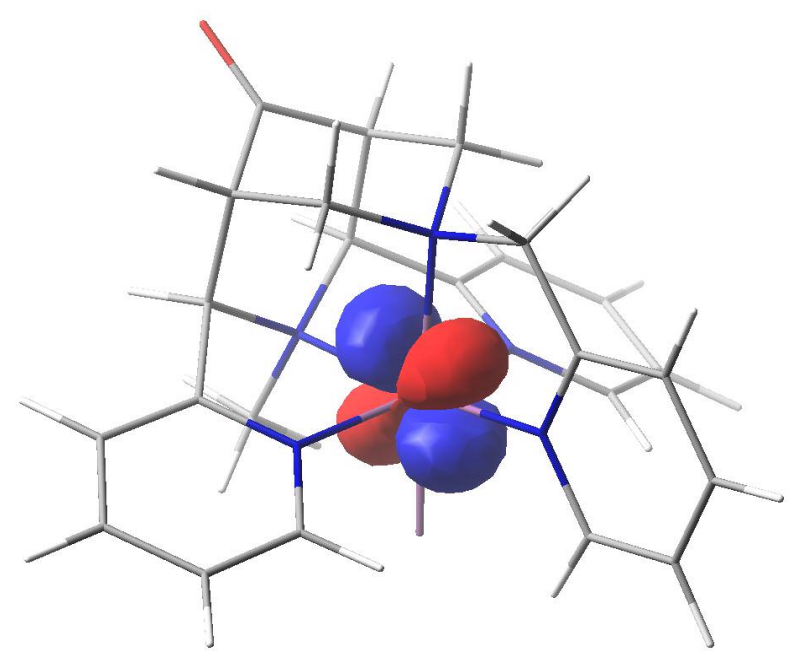

$\mathrm{d}_{\mathrm{yz}}-115$-alpha

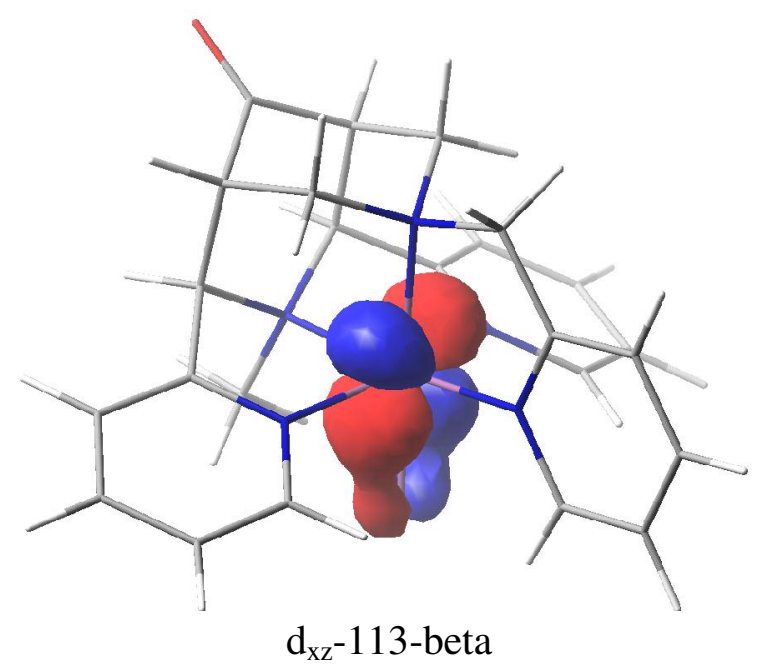

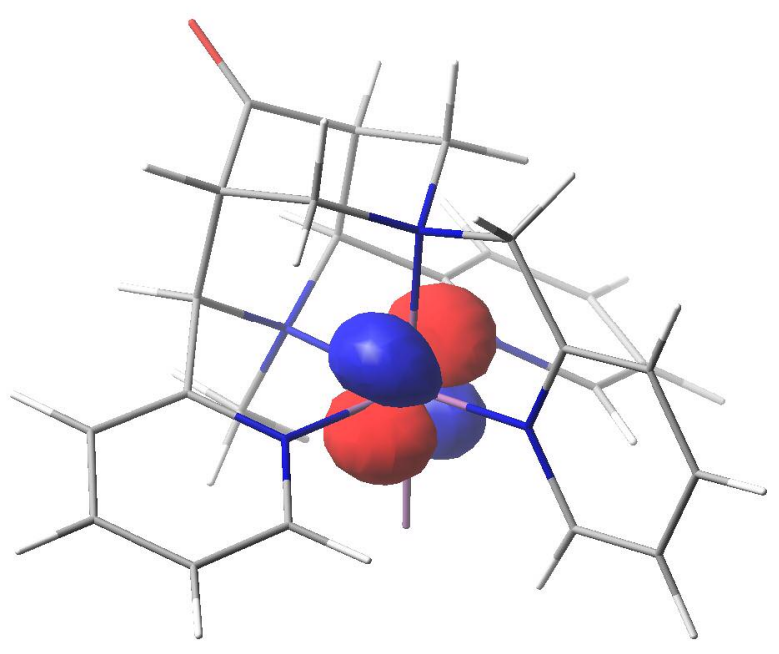

$\mathrm{d}_{\mathrm{xz}}-116$-alpha

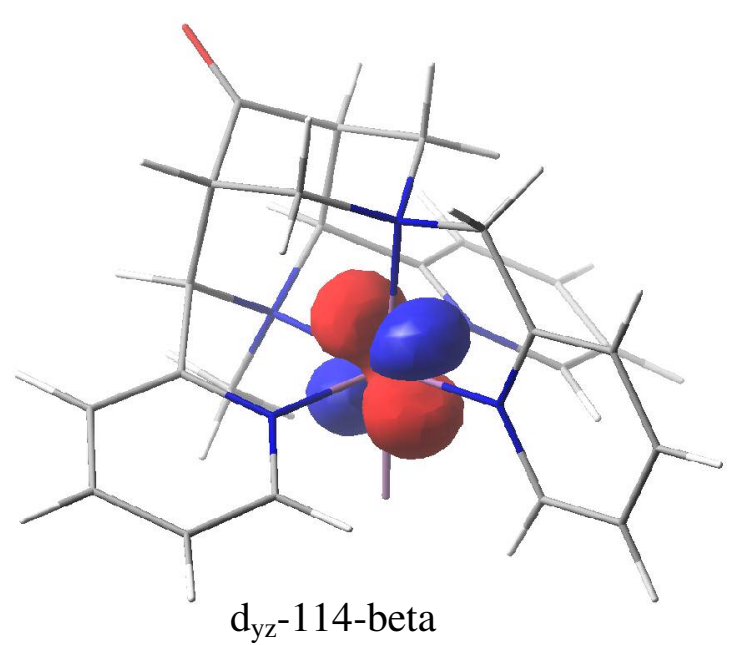

Figure SF3. Molecular orbitals of the $\mathrm{Fe}^{\mathrm{IV}}=\mathrm{O}$ unit of singlet state $\mathrm{C}$ (see Scheme $\mathrm{S} 1$ ) of $\left[\left(\mathrm{L}^{2}\right) \mathrm{Fe}^{\mathrm{IV}}=\mathrm{O}\right]^{2+}$. 

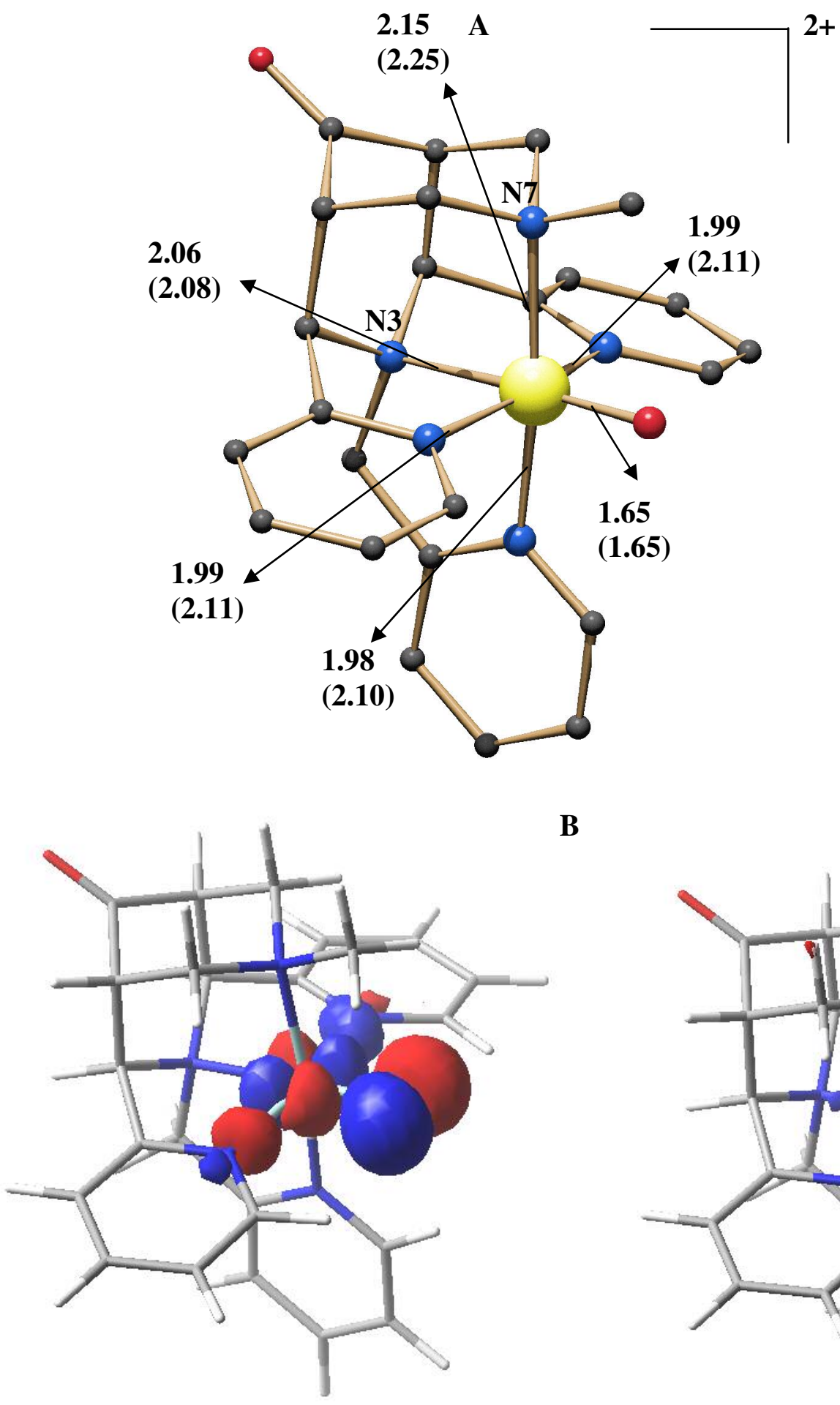

B

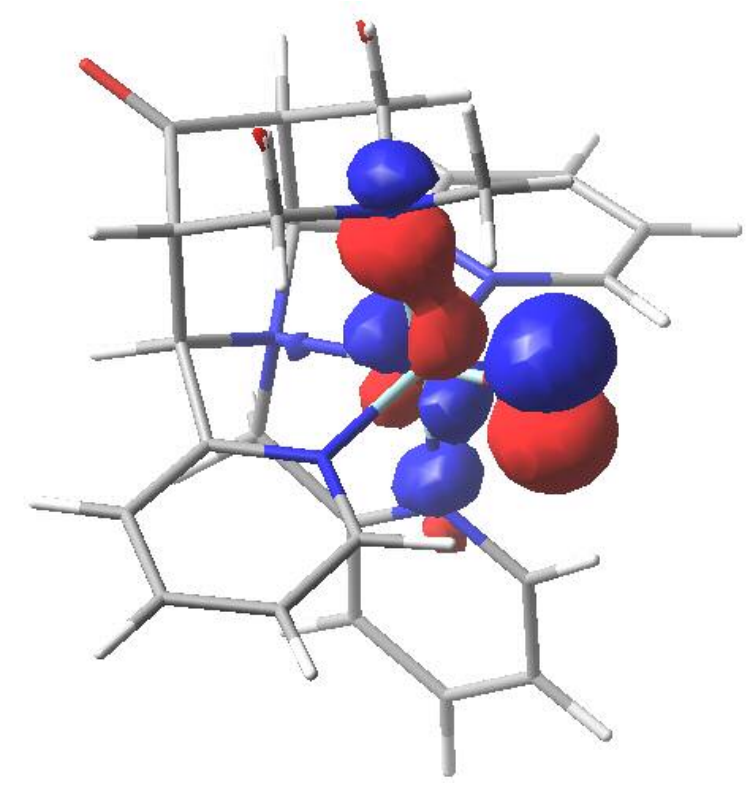

Figure SF4. a) B3LYP optimized structure of $\left[\left(\mathrm{L}^{1}\right) \mathrm{Fe}^{\mathrm{IV}}=\mathrm{O}\right]^{2+}$ in the $\mathrm{S}=1$ state (the structural parameters for the $\mathrm{S}=2$ state are given in parenthesis). b) Magnetic orbitals of the $\mathrm{S}=1$ state of the structure in a). 
The labeling experiments with the $\mathrm{L}^{2}$-based catalyst, which is discussed here in detail, reveal that $20 \%$ of the epoxide produced in aerobic atmosphere and $100 \%$ obtained under argon are due to ferryl oxygen transfer. This reaction can occur in a concerted fashion, where the olefin approaches the oxygen symmetrically, leading to transition state tsI (see Scheme 2 of the text). This directly yields the epoxide product. Previous DFT studies on a concerted insertion of oxygen into iron oxene or manganese oxene indicate that these pathways have very high energy barriers compared to a stepwise mechanism. With the bispidine ligand backbone the search for a concerted transition state with normal and QST-guided TS search procedures yielded the strongly asymmetric transition state $t s I I$ of the stepwise mechanism. Therefore, a computationally more expensive potential energy scan was carried out by varying the oxygenolefin bond distance from 1.6 to $2.7 \AA$ with a step size of $0.1 \AA$. Each structure along the scan was fully optimized. This is shown in Figure SF5. The maximum energy along the scan is at 2.1 $\AA$, and the corresponding structure was used as the initial structure for a transition state search. This leads to the concerted transition state $t s I$ with an energy barrier of $46.3 \mathrm{~kJ} / \mathrm{mol}$. However, a frequency calculation revealed two imaginary frequencies, closely associated with the required vibration. All attempts to get a first order saddle point from this structure resulted in either the transition state $t s I I$ of the stepwise reaction channel or collapsed to the product. The optimized structure of the "transition state" tsI is given as Figure SF6 in the supplementary information. 


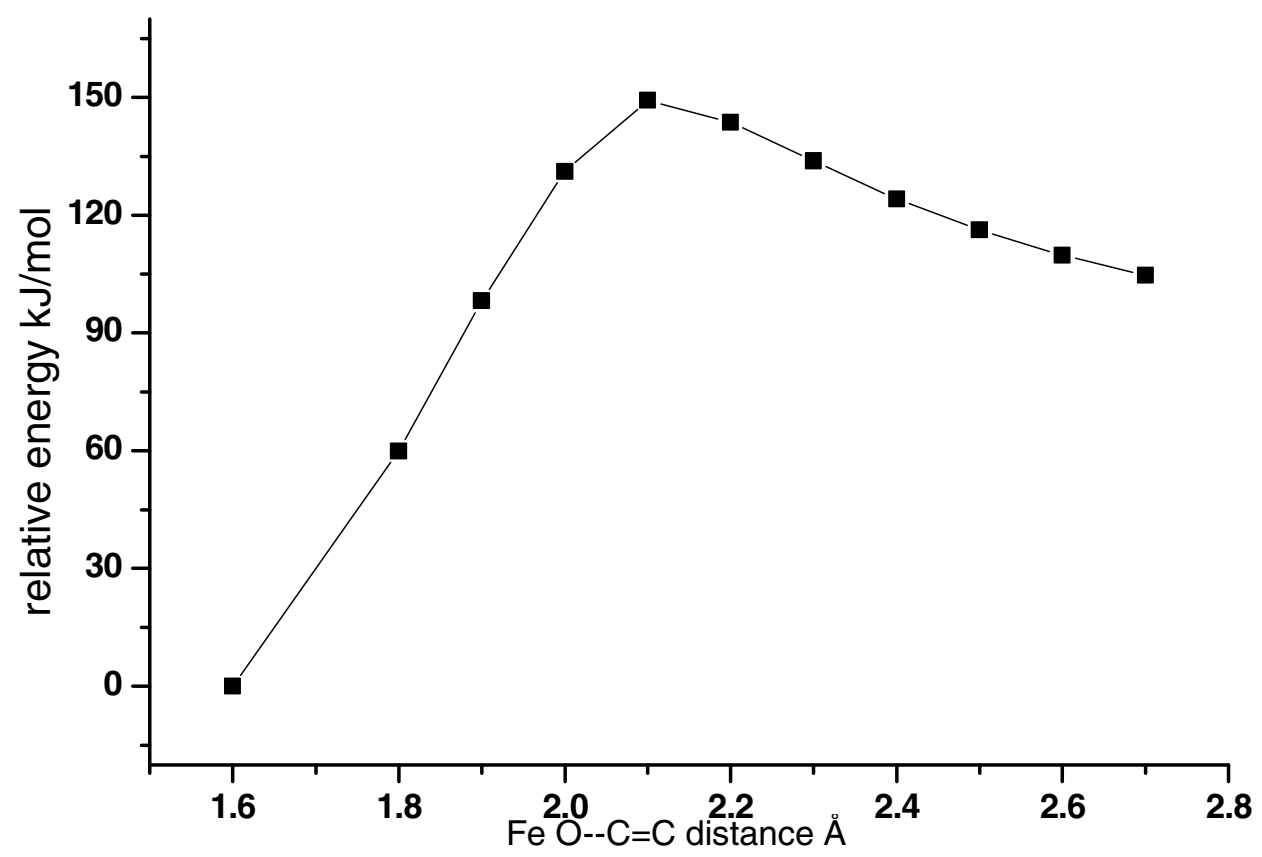

Figure SF5. Potential energy scan for the concerted epoxidation pathway along the $\mathrm{O} \ldots \mathrm{C}=\mathrm{C}$ coordinate. Each point represents a fully optimized geometry with symmetric $\mathrm{O} \ldots \mathrm{C}=\mathrm{C}$ distances.

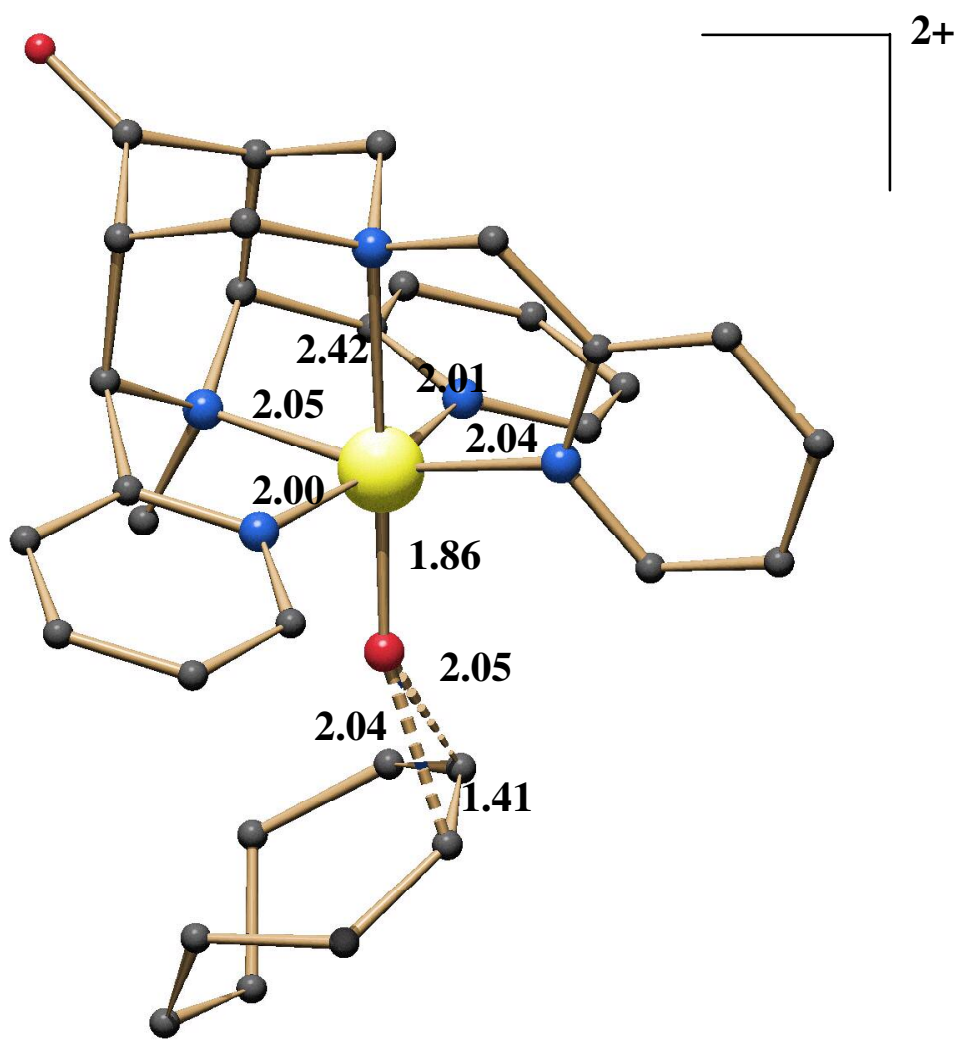

Figure SF6. The $\left[\left(\mathrm{L}^{2}\right) \mathrm{Fe}^{\mathrm{IV}}=\mathrm{O}\right]^{2+}$-system: B3LYP optimized structure of the concerted "transition state" tsl for the $S=1$ spin state. All bond lengths in $\AA$ and angles in degrees. 

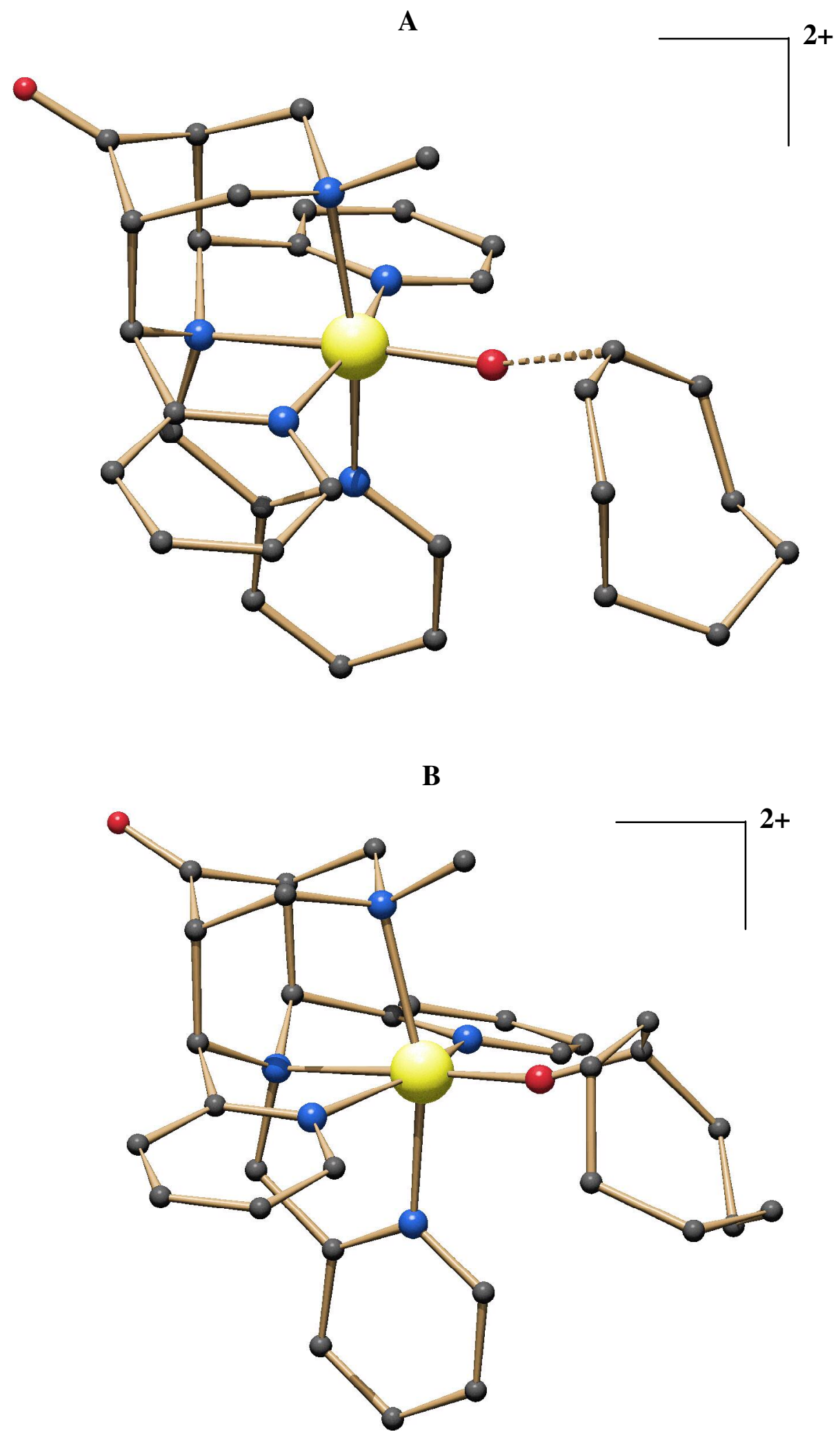


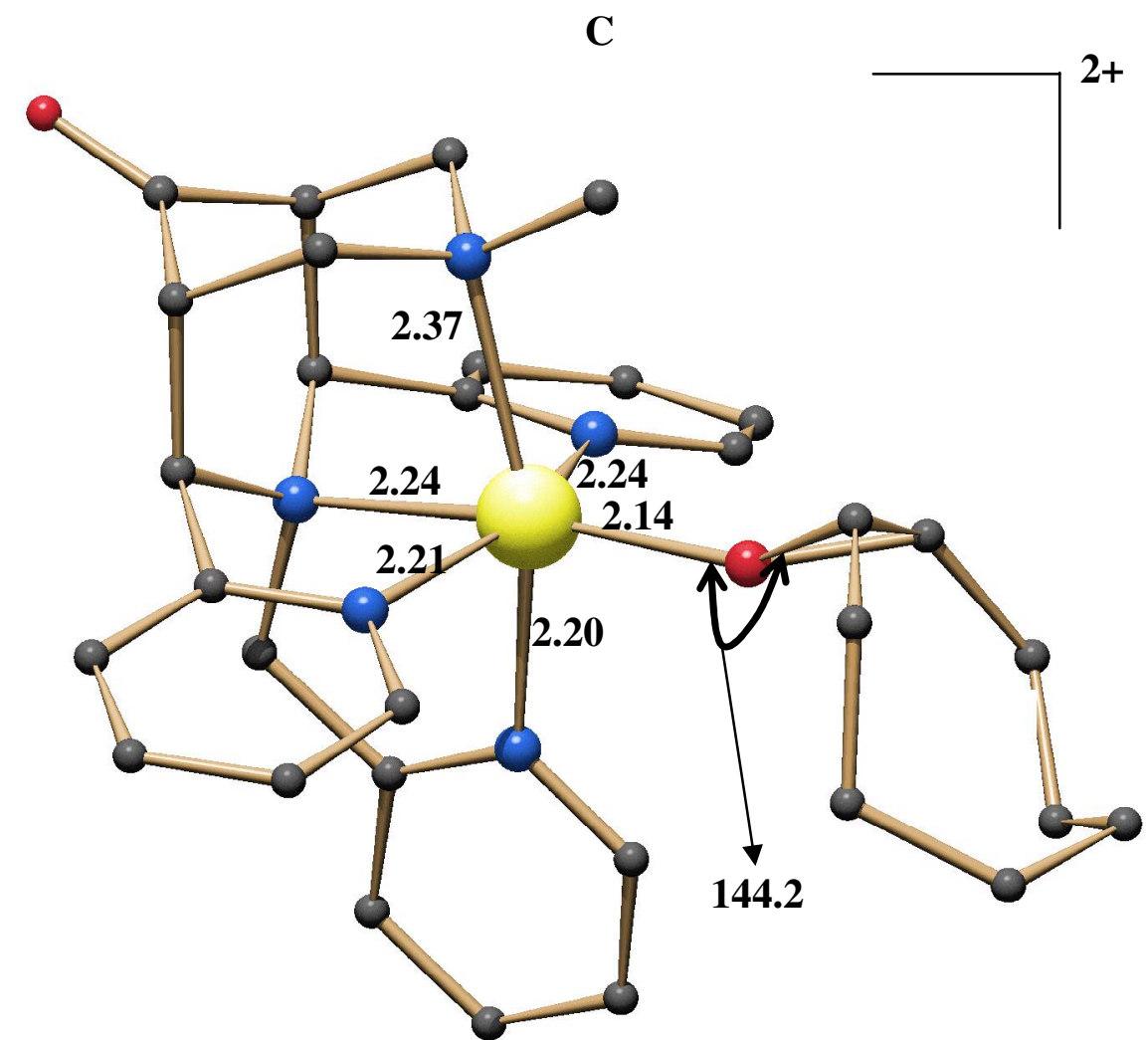

Figure SF7. The $\left[\left(\mathrm{L}^{\mathrm{I}}\right) \mathrm{Fe}^{\mathrm{IV}}=\mathrm{O}\right]^{2+}$-system: a) B3LYP optimized structure of $t$ II in the $\mathrm{S}=1$ configuration; b) intII in the $\mathrm{S}_{\mathrm{T}}=3$ configuration; c) intI in the $\mathrm{S}=2$ configuration. All bond lengths in $\AA$ and angles in degrees.

\section{Imaginary frequencies for the transition states:}

The following are the imaginary frequencies found for the calculated transitions states, $t s I$ $\mathrm{S}=1\left(-600.4 \mathrm{~cm}^{-1},-100.2 \mathrm{~cm}^{-1}\right)$, tsII $\mathrm{S}=1\left(-366.6 \mathrm{~cm}^{-1}\right), \mathrm{S}=2\left(-109.7 \mathrm{~cm}^{-1}\right)$, tsIII $\mathrm{S}=3(-873.4$ $\left.\mathrm{cm}^{-1}\right), \mathrm{S}=1$ (intermediate spin on $\left.\mathrm{Fe}\right)\left(-366.2 \mathrm{~cm}^{-1}\right), \mathrm{S}=1$ (low spin on $\left.\mathrm{Fe}\right)\left(-242.6 \mathrm{~cm}^{-1}\right)$ and for tsIV $\mathrm{S}=4\left(-707.4 \mathrm{~cm}^{-1}\right)$. Due to the difficulties in converging to the correct spin states the frequency calculation have been performed only using Jaguar on tsIII $\mathrm{S}=1$ (low spin on $\mathrm{Fe}$ ) state.

\section{Calculation of exchange interaction:}

We have used the broken symmetry model, developed by Noodleman, for the estimation of the magnetic exchange interactions in the radical intermediate (1). The main advantage of this method is that only the energies of single determinants are needed to approximate the 
energies of the whole spin manifold. For radical intermediate we have used the following equation to compute the $J$ values.

$$
J=\frac{2\left(E_{B S}-E_{H S}\right)}{S_{H S}\left(S_{H S}+1\right)}
$$

Table SF1. UB3LYP computed total energies (in Hartree) of the species along the reaction profile.

\begin{tabular}{|c|c|c|}
\hline Species & Total energy & $\left\langle S^{2}\right\rangle$ \\
\hline \multicolumn{3}{|c|}{$\left[\mathrm{L}^{2} \mathrm{Fe}^{\mathrm{IV}}=\mathrm{O}\right]^{2+}$} \\
\hline$S=0$ & -1476.3865780 & 0.000 \\
\hline$S=1$ & -1476.4349903 & 2.020 \\
\hline$S=2$ & -1476.4197277 & 6.061 \\
\hline \multicolumn{3}{|l|}{$t s I I$} \\
\hline$S=1$ & -1789.6002352 & 2.115 \\
\hline \multicolumn{3}{|l|}{ intII } \\
\hline$S=3$ & -1789.6252743 & 12.019 \\
\hline$S=2$ & -1789.6271083 & 6.904 \\
\hline$S=1$ & -1789.6003986 & 3.012 \\
\hline $\mathrm{S}=1^{\mathrm{a})}$ & -1789.6205141 & 2.028 \\
\hline \multicolumn{3}{|l|}{ tsIII } \\
\hline$S=3$ & -1789.5507582 & 12.019 \\
\hline$S=1$ & -1789.6083689 & 3.136 \\
\hline $\mathrm{S}=1^{\mathrm{a})}$ & -1789.6207028 & 2.028 \\
\hline \multicolumn{3}{|l|}{ intI } \\
\hline$S=0$ & -1789.6580907 & 0.000 \\
\hline$S=1$ & -1789.6536722 & 2.021 \\
\hline$S=2$ & -1789.6729379 & 6.009 \\
\hline \multicolumn{3}{|l|}{$t s I V$} \\
\hline$S=4$ & -1939.8577552 & 20.035 \\
\hline \multicolumn{3}{|l|}{ intIII } \\
\hline$S=3$ & -1939.9534535 & 12.017 \\
\hline \multicolumn{3}{|c|}{$\left[\mathrm{L}^{2} \mathrm{Fe}{ }^{\mathrm{IIII}} \mathrm{OOH}\right]^{2+}$} \\
\hline$S=1 / 2$ & -1552.1970809 & 0.767 \\
\hline$S=3 / 2$ & -1552.1791253 & 3.813 \\
\hline$S=5 / 2$ & -1552.1872900 & 8.763 \\
\hline \multicolumn{3}{|l|}{ tsVII } \\
\hline$S=1 / 2$ & -1865.3705894 & 1.145 \\
\hline \multicolumn{3}{|l|}{$t s V I$} \\
\hline$S=1$ & -1941.1360577 & 2.040 \\
\hline
\end{tabular}

a) Antiferromagnetic $\mathrm{S}=1$ state for the is configuration on $\mathrm{Fe}$ and spin down on the radical center. 


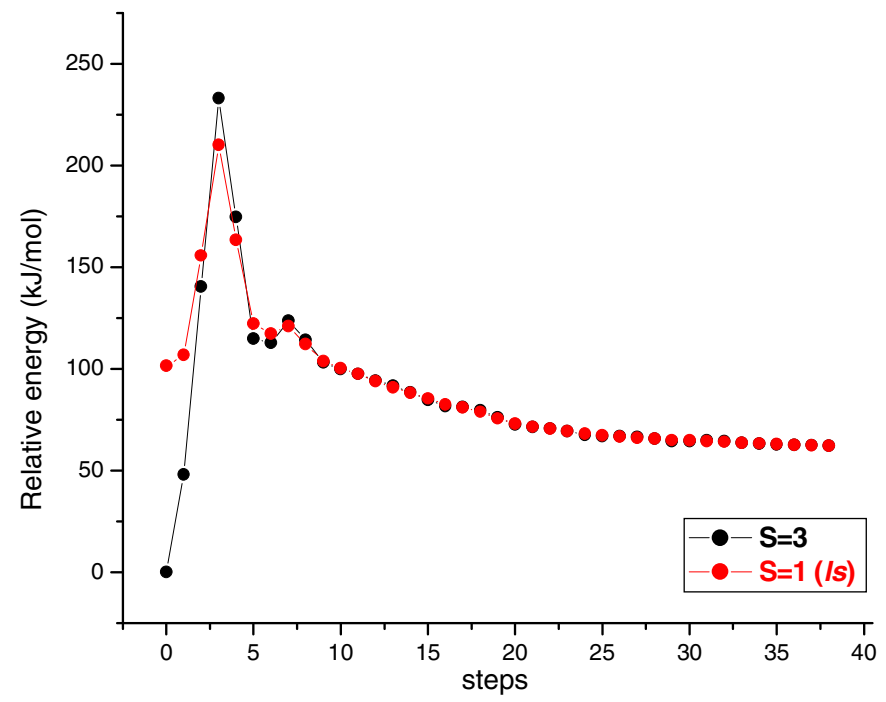

Figure SF8. Energy profile along MECP calculations for intII to tsIII from the $\mathrm{S}=3$ hs $\mathrm{Fe}^{\mathrm{III}}$ surface to $\mathrm{S}=1 l s \mathrm{Fe}{ }^{\mathrm{III}}$ surface.

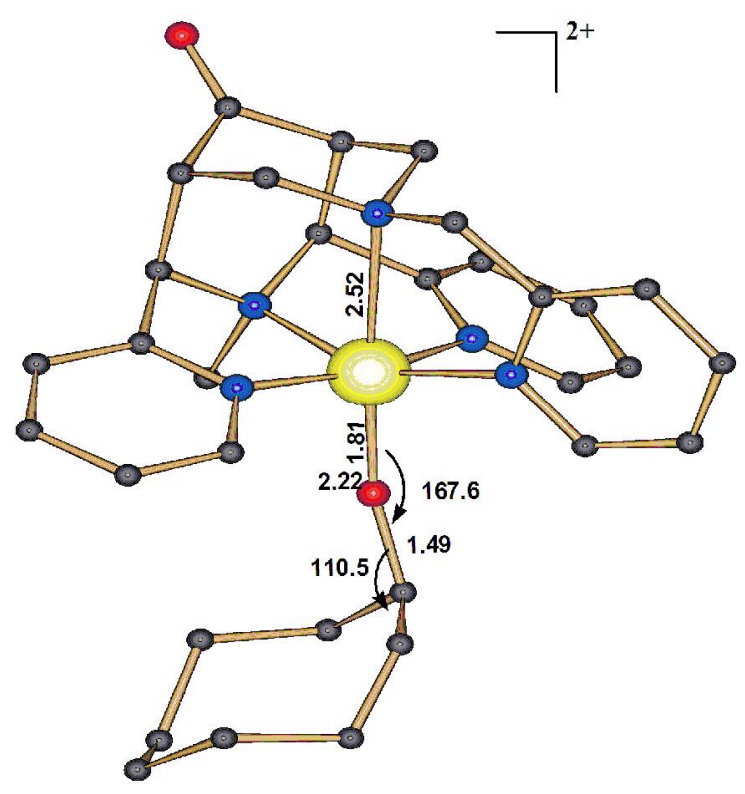

Figure SF9. The optimised structure of the MECP between the $\mathrm{S}=3 h s$ Fe ${ }^{\mathrm{III}}$ surface to $\mathrm{S}=1 l s$ $\mathrm{Fe}^{\mathrm{III}}$ surfaces.

\section{References:}

1. Noodleman, L. J. Chem. Phys., 1981, 74, 5737.; Ruiz, E.; Alvarez, S.; Rodriguez-Fortea, A.; Alemany, P.; Pouillon, Y.; Massobiro, C. in Magnetism: Molecules to Materials II, edited by Miller, J. S., Drillon, M., Wiley-VCH; Weinheim, 2001, 227. 